\title{
The race has begun! But how to learn how to race and pace?
}

\begin{tabular}{|r|l|}
\hline Journal: & International Journal of Sports Physiology and Performance \\
\hline Manuscript ID & Draft \\
\hline Manuscript Type: & Editorial \\
\hline Date Submitted by the Author: & n/a \\
\hline Complete List of Authors: & $\begin{array}{l}\text { Hettinga, Florentina; University of Essex, School of Biological Sciences, } \\
\text { Centre of Sport and Exercise Science }\end{array}$ \\
\hline Keywords: & \\
\hline
\end{tabular}




\section{The race has begun! But how to learn how to race and pace?}

\section{Florentina J Hettinga}

Very applicable, the first academic words I read this year, 2018, were the words of our new Editor Jos de Koning in the January issue of IJSPP: 'Let the Race begin'. ${ }^{1}$ Nice first words, not only very applicable in the context of sports in general, but also to me personally. Very applicable, because my own academic race began a while ago now in the early 2000s, in the initial stages of the race nicely drafting in the slipstream of my then MSc supervisors: IJSPP Editors Jos de Koning and Carl Foster. And even more applicable: my work was on the topic of racing and pacing. ${ }^{2,3,4}$

As a young academic, academic 'racing' and also pacing is something an emerging scientist, researcher and academic needs to learn: how to achieve optimal results, how to plan activities and effort distribution, how to deal with different competitive environments, and how to learn from mistakes, to name just a few. Already then, I was intrigued by the concept of pacing in this broader sense, not only specifically relevant to sports performance, but an interesting concept underlying behaviour, decision-making and performance in life more generally.

Sports environments are from that perspective ideally suited to provide us with an opportunity to study large data collections on how humans behave, decide and perform under physically challenging circumstances. Sport is in the end all about 'optimizing productivity' on a well-defined and relatively simple standardized performance task in a standardized and controlled setting, often performed under standardized conditions involving indoor tracks and accurate timing measurement equipment as demonstrated in short track speed skating recently. ${ }^{5}$ Fairness in environmental circumstances, accurate measurability of performance and fair comparison against other competitors are crucial aspects of competition but also happen to be important aspects in the design of experimental studies. Therefore, exploring data collected in the world of sports competition are not only very relevant to applied sports practice, but can have wider impact in other domains in which human performance, productivity, behaviour and decision-making are of interest.

A recent study for example focused on exploring short track skating performance, in which it was shown that a qualification system involving repechage placements could disadvantage riders who had to compete twice per day. ${ }^{6} \mathrm{~A}$ second paper focused on exploring different competitive circumstances and their impact on pacing behaviour, finding that the more competitors were in the race, the faster the initial phase of the race would be completed. ${ }^{7}$ Apart from the practical relevance of these findings for sports practice, and the potential impact on competition design, these studies could be attractive to a more general audience because they explore more general questions of how humans behave in different competitive environments and how preceding exercise might impact on productivity.

Lastly, to return to the topic of pacing and racing in young individuals: also this is a topic of broader interest. How do young individuals under challenging circumstances learn how to distribute their energy and activities? Sport is an ideal situation to study this question. However, in the sports domain, not many studies have focused on how pacing skills develop from childhood throughout adolescence. In our recent invited commentary ${ }^{8}$ we brought together literature on pacing, talent development and self-regulation of learning. Not only is self-regulation essential throughout the process of reaching the long-term goal of (athletic) excellence, but it also seems crucial for the 
development of pacing skills within a race. Coaches and trainers are advised to incorporate pacing as a performance characteristic in their talent-development programs by stimulating their athletes to reflect, plan, monitor, and evaluate their races on a regular basis to build performance templates and improve their performance.

The above studies, as well as the many studies published in IJSPP since its founding in 2006, have focused on exploring sports physiology and performance, appreciating a multi-disciplinary approach and the uniqueness and challenges of collecting field data of elite performers. This work has provided an invaluable wealth of knowledge on sports performance and coaching throughout the years, that has been very relevant to sports practice. We should not forget the wider impact that multidisciplinary studies in the field of sports performance could have into other domains involving for example competition, productivity, optimising performance, learning and decision-making.

Let the race continue!

\section{References}

1. de Koning, JJ. Let the race begin! Int J Sports Physiol Perform. 2018;13:1-1.

2. Foster, C, De Koning, JJ, Hettinga, FJ, Lampen, L, La Clair, KL, Dodge, C, Bobbert, MF, Porcari, JP. Pattern of Energy Expenditure during Simulated Competition. Med. Sci. Sports Exerc. 2003;35(5):826831.

3. Foster, C, De Koning, JJ, Hettinga, FJ, Lampen, J, Dodge, C, Bobbert, MF, Porcari, JP. Effect of competitive distance on energy expenditure during simulated competition. Int J Sports Med. 2004;25: 198-204.

4. De Koning, JJ, Foster, C, Lampen, J, Hettinga, FJ, Bobbert, MF. Experimental evaluation of the power balance model of speed skating. J Appl Phys. 2005;98(1):227-233.

5. Noorbergen, OS, Konings, MJ, Micklewright, D, Elferink-Gemser, MT, Hettinga, FJ. Pacing behavior and tactical positioning in 500-and 1000-m short-track speed skating. Int J Sports Physiol Perform. 2016;11(6):742-748.

6. Konings, MJ, Hettinga, FJ. Preceding Race Efforts Affect Pacing and Short-Track Speed Skating Performance. Int J Sports Physiol Perform. (in press). doi.org/10.1123/ijspp.2017-0637

7. Konings, MJ, Hettinga, FJ. The Impact of Different Competitive Environments on Pacing and Performance. Int J Sports Physiol Perform. (in press). doi:10.1123/ijspp.2017-0407

8. Elferink-Gemser, MT, Hettinga, FJ. Pacing and Self-regulation: Important Skills for Talent Development in Endurance Sports. Int J Sports Physiol Perform. 2017;12(6):831-835. 